\title{
Too much computer and Internet use is bad for your grades, especially if you are young and poor: Results from the 2001 Brazilian SAEB
}

\author{
Jacques Wainer* \\ Institute of Computing, UNICAMP, Brazil \\ Tom Dwyer \\ Department of Political Science, UNICAMP, Brazil \\ Rodrigo Silveira Dutra \\ Department of Mechanical Engineering, UNICAMP, Brazil \\ Andre Covic \\ Institute of Computing, UNICAMP, Brazil \\ Valdo B. Magalhães \\ Department of Political Science, UNICAMP, Brazil \\ Luiz Renato Ribeiro Ferreira \\ Department of Political Science, UNICAMP, Brazil
}

Preprint submitted to Elsevier Science

2 April 2008 


\title{
Valdiney Alves Pimenta
}

\author{
Institute of Computing, UNICAMP, Brazil
}

\section{Kleucio Claudio}

Department of Electrical Engineering, UNICAMP, Brazil

\begin{abstract}
This work presents the analysis of the 2001 Brazilian Basic Education Evaluation System (SAEB) achievement exam. The SAEB tested 4th, 8th, and 11th grade students, in mathematics and reading (Portuguese). We classified the students into seven socioeconomic classes, and for each class, compared the test results according to frequency of computer use, computer ownership, Internet access at home, and whether the teachers used computers and Internet as pedagogical tools. Frequency of computer use had, in general, a negative effect on the test results, and the negative effect increased for younger and poorer students. Computer ownership had, in general, a small positive effect on the test results for older students, and no effect for 4th graders. Internet access had a negative effect for younger and poorer students, and a positive effect for 11th graders. Finally, whether the teacher used computers or Internet as pedagogical tools had no effect on the student's test results for all social economic classes and grades.
\end{abstract}

Key words: evaluation methodologies, elementary education, secondary education, country-specific developments

\footnotetext{
* Corresponding author: Jacques Wainer, Instituto de Computação, Universidade Estadual de Campinas, Caixa Postal 6176, 13083-970 Campinas - SP, Brazil. Fax: $+55-19-35215847$.

Email address: wainer@ic.unicamp.br (Jacques Wainer).
} 


\section{Introduction}

There are a large number of government and private initiatives to provide computers or computer access to poor students, especially primary and secondary school students. The dominant view in public policy circles is that the introduction of computers and Internet access in students' schools and possibly in their homes and communities, will improve learning. Therefore, this view advocates, such initiatives should be encouraged or adopted by governments.

One of the most publicized initiatives of this kind is One Laptop per Child ${ }^{1}$ (OLPC) spearheaded by Nicholas Negroponte, of Massachusetts Institute of Technology Media Lab, which proposes the development of a laptop that would cost around US $\$ 100$ and would be bought by governments and nongovernmental organizations to be distributed to poor children around the world. The project has been presented and publicized in the Davros Economic Forum, the World Summit on the Information Society in Tunis, and other venues. The OLPC site lists Brazil, Thailand, Egypt, the United States, Cambodia, the Dominican Republic, Costa Rica, Tunisia, Argentina, and Venezuela as committed to the project, in different ways.

All these initiatives are based on the belief that computers, either in school or at home, help students learn. Surprisingly, very little research has been done on the subject, and the sparse research on the topic supports contradictory conclusions.

This research analyzed data from the 2001 Brazilian Basic Education Evaluation System (SAEB), a national, sample based achievement test. The 2001

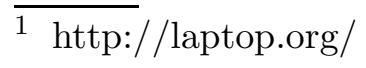


SAEB not only tested students in reading and mathematics, but also asked the students questions about frequency of computer use to help in assignments, ownership of computers and Internet access in the home. In parallel, teachers of the selected students were asked about their use of computers and the Internet as pedagogical tools. Thus, the 2001 SAEB is a unique source to verify whether the use of computers and the Internet by students and teachers is correlated with better results in the test grades.

Computer ownership and Internet access are also correlated with the socioeconomic status of the student's family (richer families are more likely to own a computer than poorer ones) and the socioeconomic status of the family is correlated with the student's educational achievement. To control for this factor, we classified the students in seven socioeconomic classes and compared the test grades within each class.

The question about frequency of computer use was not repeated in the 2003 SAEB, so unfortunately we were unable to perform a longitudinal analysis of that issue.

\subsection{The $S A E B$}

The Brazilian $\mathrm{SAEB}^{2}$ is an achievement test in reading and mathematics that is administered every 2 years on a randomly selected set of students from the 4th, 8th, and 11th grades ${ }^{3}$. The exam has been administered systematically since 1995. The students answer the test questions on either mathematics or reading and also answer a questionnaire about their socioeconomic status,

$\overline{2}$ http://www.inep.gov.br/basica/saeb/ingles.htm

3 The 11th grade is the last grade of secondary education in Brazil 
family values and attitudes towards education, and study habits. The students' teachers answer a questionnaire about their teaching habits and qualifications, and the schools' principals answer a questionnaire about school infrastructure. The SAEB data do not identify the students but allow each student's test and questionnaire responses to be linked with his or her teacher's questionnaire responses, and the principal's responses.

The SAEB exam is similar to other well-known evaluation exams, such as the American National Assessment of Educational Progress (NAEP) and the international Programme for International Student Assessment (PISA). PISA has a 3 year cycle, and selects one area for each test year (reading in 2000, mathematics in 2003, and science in 2006). NAEP has a 2 year period, and in each test year two subjects are selected from among reading, mathematics, science, writing, U.S. history, civics, geography, and the arts.

Data from the SAEB have been used by Soares et al. (2000) to analyze the influence of family values on school achievement, and by Soares and Alves (2003) to analyze the influence of race on school achievement. The SAEB as been criticized on more ideological grounds by de C. P. Santos (2002) as fostering a measure-oriented approach to education.

\subsection{Previous research on the impact of computers on school achievement}

We conducted a number of qualitative empirical studies in schools (Dwyer, 1997, 2003) and became intrigued by what we observed: Computer use often was not clearly associated with positive educational outcomes. However,we

had no information on the relationship between these local case studies and 
the more general picture. When we searched the Brazilian national literature, the general hypothesis in operation seemed to be that computer use would improve educational performance, but very few studies sought to verify this hypothesis.

Our next step was to analyze the international literature. We found two main lines of research on the impact of computer use in primary and secondary education. The first line evaluates specific tools, such as computers and software, designed to enhance the learning of a specific subject topic. This line of research usually relies on experimental or quasi-experimental designs to measure the effect of the particular teaching tool on the student's grade on a test on the specific topic, and compares it with a control group that did not use the tool.

The second line of research studies the differences in academic achievement in large populations, comparing the groups of students who declared themselves to be computer users (or who go to schools where computers are available) with the group of non-computer users. In this case, statistical analysis is the only method available, and therefore no clear causal connection between computer use and grades can be established. This research follows the second line.

In the first line of research, a recent meta-analysis (Kulik, 2003) analyzed the results of controlled experiments on the use of some form of computer technology in teaching reading, writing, science, and math, published in the 1990s. The meta-analysis first concluded,

Although many researchers have carried out controlled evaluations of technology effects during the last three decades, the evaluation literature still seems patchy. For most technologies, results are available only at selected 
grade levels, in selected subjects, and on selected instructional outcomes. The literature is too uneven for sweeping conclusions about the effectiveness of instructional technology.

The meta-analysis then reached some tentative conclusions. In reading, neither Integrated Learning Systems nor Writing to Read seemed to make any contribution to reading achievement whereas reading management programs seemed to have a more positive record. In writing, most results showed a positive impact of computer technology on writing skills. In math and science, computer tutors consistently showed improvements in students' learning, but simulation programs and microcomputer-based laboratories resulted in both negative and positive results in almost the same proportions.

We will now discuss the published work in the second line of research by referring to some results from the NAEP. Wenglinsky (1997) used data from the 1996 NAEP which included mathematics and concluded that the way in which the students used computers affected on their test results in 8th grade but not in 4th grade. The author divided the students who used computers into a group who used it to "develop higher-order skills" and those who used computers only for "drill and practice." The author concluded that the former group had higher grades than the students who did not use computers, and the latter had lower grades than those who did not use computers. However the author neither observed nor directly measured these two forms of computer use, they were inferred from the teachers' qualifications. The author presupposed that more qualified teachers were educating their students to use the computer to "develop higher-order skills" and that the less qualified teachers used computers for "drill and practice." 
Johnson (2000) followed on from this research, using the 1998 NAEP data, and verified that race, gender, socioeconomic class, and parents' education all have a statistically significant impact on the reading test scores of 4 th and 8th graders, but whether the students did or did not have computer classes at least once a week, under the supervision of a trained teacher, did not have a statistically significant impact. Johnson (2000) can be seen as undermining the assumptions put forth in Wenglinsky (1997) because only fully qualified teachers were included, that is, teachers who used computers to "develop higher-order skills" in their students. However, such computer use had no statistical impact on the students' grades.

A government-sponsored study in the United Kingdom (Harrison et al., 2003) evaluated the impact of computer use both at school and at home, using the British Key Stages 2, 3 and 4 tests. Among 7-year-old children, the study found a small but statistically significant positive correlation between English test results and the use of computers but no such correlation for mathematics. There was no statistically significant correlation among 12-year-old children for any subject, and among 15-year-old children a positive and significant correlation was found between the use of computers and the test results in science and "design and technology".

A recent report by the Organization for Economic Cooperation and Development (OECD, 2006) analyzed the 2003 PISA data (which tested mathematics) and concluded that among 15-year-old,

- Students with limited access to computers performed below average on the test. Students with no computers at home had a below-average proficiency level, even when socioeconomic background was taken into consideration 
(for most countries).

- Students with low proficiency with computers performed poorly on the 2003 PISA

- Students who reported a medium frequency of computer use performed better than the ones reporting a low or high frequency of computer use.

These studies, though slightly favorable to the hypothesis that computer use has a statistically significant positive effect on school performance as measured by standardized tests in a variety of subjects, raise the question of whether the slightly positive results found in industrialized countries will also be found in developing countries. This study addresses this question.

\section{Method}

In this research we analyzed the 2001 SAEB data and focused on the grades obtained and their relationship to the three questions that were asked of students and the two questions asked of teachers about computer and Internet use.

Question 28 of the second questionnaire for 4th graders translates as follows:

Do you use computers to do the homework or other assignments asked by the math teacher?
a) Always
b) Almost always
c) Seldom
d) Never 
We abbreviate the answers as A (always), F (frequently or almost always), S (seldom) and $\mathrm{N}$ (never).

Question 22 of the first questionnaire for 4th graders translates as follows:

How many of the following items are there in your home (mark the corresponding quantity for each item or zero if there are none)?

22) Computer
a) 0
b) 1
c) 2
d) 3
e) 4 or more

We grouped answers b) through e) into a single variable that indicates that the student has at least one computer at home.

Question 28 of the same questionnaire translates as follows:

Of the following items, are they present in your home (mark YES or NO for each line)?

28) Internet YES NO

The teachers' answers of relevance to this research were for questions 86 and 87, which translate as follows:

Items 86 to 95 present a list of a few pedagogical resources Indicate whether you use them IN THE SCHOOL: 
86) Internet access for the students

a) Yes, I use it.

b) I do not use it because it is not available in the school, but I find it necessary.

c) No, I do not use it.

87) Computers for use by students

a) Yes, I use them.

b) I do not use them because they are not available in the school, but I find them necessary.

c) No, I do not use them.

We abbreviate these answers as $\mathrm{Y}$ (yes), W (I want to use), and $\mathrm{N}($ no).

\subsection{Socioeconomic class}

The Brazilian association for market research companies developed a standard method to classify families into one of seven socioeconomic classes (CCEB, 2003) named A1, A2, B1, B2, C, D, and E, from richest to poorest, according to material possessions and education. In recent urban surveys, the socioeconomic classes represent 1\%, 5\%, 9\% 14\% 36\% 31\% and $4 \%$ of the population respectively.

The socioeconomic questionnaire administered to students included almost 
all items needed to calculate the student's socioeconomic class, except the item related to the educational level of the head of household. The student questionnaire asked for the mother's and father's education levels, and we opted to use the higher of them as indicating the educational level of the head of household (even though this may have overestimated the socioeconomic class of the student).

\subsection{Excluded data}

From the original SAEB sample of 287,719 students, we eliminated all records where missing data did not allow us to calculate the socioeconomic class of the student, and all records with missing data on the questions of interest in this research. Furthermore, we excluded all students from private schools and all from socioeconomic class A1. The exclusion of students from private schools was motivated by the fact that government programs to introduce computers into schools are geared toward public schools. Public schools in Brazil include a greater proportion of the poorer population, and their teachers generally are considered to be less well paid, less motivated, and less qualified than their counterparts in private schools.

The reasons for excluding students from the socioeconomic class A1 were mainly aesthetic: there are only about 200 records of A1 students in public schools tested by the SAEB, and therefore the confidence intervals for measures in this class would be large, so it is very likely that no statistically significant results would be found. Furthermore, we were interested in the vast majority of students, who come from poorer families, and the inclusion of more wealthy students would make the results regarding the poorer students 
less evident. A total of 126,609 students were left in our study. Table 1 displays the distribution by grade and socioeconomic class of these students.

Finally, our results did not distinguish between students who took the mathematics and reading tests. We found that there was no important difference between the two groups.

\subsection{Confidence intervals}

In this article, all confidence levels are 95\%. Confidence intervals are adjusted using the Bonferroni correction, a common multiple comparison procedure (e.g. Bland and Altman (1995); Abdi (2007)).

The main problem in comparing more than two sets of data is that one is more likely to reject the null hypothesis when it is true, that is, to find that the sets have different means when in fact they do not. If $k$ independent comparisons are made, and each comparison is made with the significance level $1-\alpha$, then the probability of wrongly rejecting the null hypothesis is $1-(1-\alpha)^{k}$. For example, if one is comparing five sets of data (and thus there are 10 pairwise comparisons), and each comparison is performed with a $95 \%$ significance level (and thus $\alpha=.05$ ), then there is at least a $40 \%$ chance that one of the tests will be declared significant when it is not. But if the confidence level is $95 \%$, one expects the probability of making that mistake to be at most $5 \%$.

Thus, when one is performing $k$ comparisons, the comparisons must be made with a low $\alpha$ to minimize the probability of detecting differences that are not present. The Bonferroni correction is a simple procedure that sets the $\alpha$ of each pairwise comparison to $\alpha / k$. If $n$ populations are to be compared, there 
are $n(n-1) / 2$ pairwise comparisons. To achieve a global significance level of $1-\alpha$, each pairwise comparison is made at the significance level $1-\frac{\alpha}{n(n-1) / 2}$. For example, in figure 1 each vertical bar for each socioeconomic class indicates a $1-\frac{0.05}{4 \times 3 / 2}=99.2 \%$ confidence interval on the mean grade.

\section{Results}

\subsection{Student's use of computers}

Figure 1 displays, for each grade and socioeconomic class, the average test grade for the students, against the frequency of computer use for assignments.

The horizontal direction lists all 6 socioeconomic classes from A2 to E. The vertical direction separates the three grades, the top row for 4 th grade, the middle row for 8th grade, and bottom row for 11th grade. Let us call each combination of grade and social economic class a block. The top, leftmost block in Figure 1 refers to 4th grade students in the socioeconomic class A2. The four vertical bars are the Bonferroni corrected, 95\% confidence interval for the mean test grade. The bars represent the four possible answers to the question of frequency of computer use to do assignments. The answers are listed on the horizontal axis, as N, S, F, and A for, Never, Seldom, Frequently, and Always. Finally, the center of the confidence intervals indicates the average the grades.

Among 4th graders from socioeconomic class A2, the average test grade for students who never use computers is lower than the average test grade for students who use computers infrequently, but the difference is not statisti- 
cally significant, which indicated by the fact that the two confidence intervals have some intersection. Similarly, although the mean test grade for students that use computer frequently is lower than that for students who use it infrequently, again the differences are not statistically significant. In fact, the only statistically significant difference in this block is that between students who always use computers in assignments and students who use it infrequently.

For classes B1 and B2, the group that always use the computer has statistically significant lower grades when compared with the other groups, which do not differ among themselves. For the $\mathrm{C}$ socioeconomic class, the test results for the groups who use computer frequently and always are significantly worse that those of the other two groups. Finally in classes D and E, the group that never uses computers for their assignments has higher scores than all groups of computer users.

For the 8th grade (middle row in Figure 1), again there is a significant decrease in the average test results for those who always use the computer in comparison with the group that never uses it, for classes $\mathrm{C}$ and D. For the 11th grade, the only significant difference is for class D students, and once again we observe a decrease in the average test result for those who always use computers when compared to those who never use it.

\subsection{Student's ownership of computers and Internet access at home}

Figure 2 displays the results of the average test result as a function of whether the student has at least one computer home, and Figure 3, whether he/she has Internet access at home. 
Among 4th graders, for all socioeconomic class there is no statistically significant difference in the result according to whether the 4th grader has at least on computer home. For Internet access at home, the results are quite surprising, for classes C, D, and E, home access is associated with a significant decreases in the test results.

For the 8th grade, ownership of a computer is associated with an increase in the test results for students from classes B2 and C, but not for the other socioeconomic classes. Internet access at home is associated with a decrease in the results obtained by students from the lower classes (D and E), and has no effect for the other classes. Among 11th graders, computer ownership is associated with an increase in the test results for students who belong to classes B2, C and D, whereas Internet access is associated with an increase in the results for all socioeconomic classes, except E.

\subsection{Teacher's use of computers and Internet}

Figure 4 summarizes the effect of the teacher's use of computers as a pedagogical tool, and Figure 5, the effect of the teacher use of the Internet. The possible answers for these questions were "Yes", "No but I would like to use it," and "No," abbreviated as Y, W, and N.

For all three grades, for all socioeconomic classes, the use of computer and Internet as pedagogical tools by the teachers has no impact on the students' scores. 


\section{Discussion}

This research presented some statistical evidence that undermines the dominant view held in public policy circles, that computers and the Internet are useful in primary and secondary schools, and that these technologies will be particularly useful for the poorer students.

To a certain extent this result appears to be similar to that found in economic literature on the "productivity paradox", whereby increased investments by companies in computing were found not to always result in increased productivity (David, 1990; Triplett, 1999). Just as a series of explanations for this paradox have been developed, and we believe that a number of explanations can be developed for the results uncovered here.

But before advancing into the terrain of explanations, the statistical evidence uncovered must be considered in more depth. First, from the results one cannot claim that a frequent use of computers to do homework, or that the ownership of computer cause a decrease in the student's academic achievement. This research does not reveals a causal connection between these variables, only a correlation. Very likely there are confounding variables that can help explain the observed decrease in achievement.

\subsection{Main results of this paper}

Let us now discuss some of the more notable results of this research.

With respect to the frequency of computer use for assignments, it is almost always preferable not to use computers at all, rather than to use them always, 
or frequently. The decrease in test performance associated with an increase of computer use is more significant the younger and the poorer the student is. For socioeconomic classes C and D, even for 11th graders, there is a significant decrease in the grades of those who use computers more frequently when compared with those who never use computers for assignments. In the worst case, for 4th grades from the E socioeconomic class, the poorest, there is a $15 \%$ reduction in test scores.

Our previous research suggested are some plausible explanations for this result. In the first place, it is likely that teachers do not necessarily create assignments that can be done with the help of a computer. We found two orientations behind this: first (especially in public schools) teachers used the fact that few students had access to computers at home as a reason for not proposing assignments that could be done using the computer. Should students insist on using the computer in such cases, they could be wasting their time. However, another reason was also mentioned. In our earlier field studies students and teachers referred to the use of the Internet to "cut and paste" assignments, in other words, for plagiarism. Such a practice, if undetected, would result in good marks for take-home assignments but low benefits in terms of learning, and thereby account for poor results in examinations where cheating is not an option.

A further possible explanation is that those who use the computer for assignments also use it for many other things, and therefore have less spare time available for homework and learning than those who do not use computers. Finally, in some cases, computer use may be associated with the acquisition of skills that are not included in the standardized tests (e.g. music, art, web-page design). 
It is important to note that computer ownership seems to be correlated to a small increase in the test scores for the older students. 4th graders appear to gain nothing from having a computer home, regardless of their socioeconomic class. But Internet access is correlated with a decrease in the test results of younger students (4th and 8th graders), and the poorer the student the more significant the decrease. Among 4th graders who belong to the E socioeconomic class there is a decrease of $14 \%$ in the test achievement score of those students who have access to Internet. Older students appear to reap greater benefits of Internet use than their younger counterparts. This is clear when one considers that for 11th graders Internet access is correlated to an increase in the test scores.

The explanations for the effect of Internet access at home are similar to the explanations above. There may not be pedagogically interesting Internet sites for 4th grades, and therefore a 4th grader that spend time in the Internet is not using this time for educational purposes. Furthermore, access to the Internet by young students may also end up fostering plagiarism, which again has a negative effect on the student's educational achievement. On the other hand, the Internet seems to be a useful source of knowledge for the important topics in the 11th grade curriculum, and access to this source improves the student's educational achievement.

Finally, whether the teacher used computer and Internet as pedagogical tools in the school, had not effect on the students' test result. There are at least two possible explanations for this result. First, there may not be enough computer programs and Internet sites, in Portuguese, that are useful as pedagogical complements to the most important topics in the math and reading curricula, for primary and secondary education. Second, the teachers in the Brazilian 
public schools may not have the appropriate training to use such tools, even if there are enough of them available.

\subsection{Related works}

This research partially agrees with other similar studies Johnson (2000); OECD (2006); Harrison et al. (2003) discussed above. Table 2 compares the conditions and variables used in this study and in Johnson (2000); OECD (2006) and Harrison et al. (2003). In Table 2, the row variables lists all variables taken into consideration by the studies, and the row socioeconomic indicates whether the studies correct the results for the student's socioeconomic status.

In general, our study is more precise regarding the socioeconomic status of the student. We divided the students into seven standard classes. Johnson (2000) classified students into two socioeconomic classes (poor and non-poor), and OECD (2006) did not make it clear how the results were adjusted regarding the student's socioeconomic status.

Johnson (2000) found no impact on the grades whether the student used computers in the classroom among 4th and 8th grades. The closest variable in our study is whether the teacher used computers as a pedagogical tool (in the school), and we also found no impact on the students' grades for all ages and socioeconomic classes (Figure 4).

Among 11-year-olds, Harrison et al. (2003) found a positive influence of high frequency of computer use for English, but no impact for math and science. Among 10-year-olds we found, in general, a negative impact of the frequency of computer use in the grades, which was more salient, the lower the socioe- 
conomic status of the student (Figure 1). Among 14-year-olds, Harrison et al. (2003) found a positive impact only in sciences. For students this age, we found no impact of the frequency of computer use, with the exception that for some of the lower socioeconomic classes, students with high frequency of computer use preformed worse than the other students. Finally, among 17year-olds, Harrison et al. (2003) again found a positive impact on sciences, but not on the other subjects, and we found, in general, no impact, positive or negative, with the exception that for some of the poorer socioeconomic classes, the most frequent users had lower grades than students that used the computer less frequently (Figure 1).

OECD (2006) found that among 15-year-olds access to computer at home had a positive impact in 23 of 31 countries, even when the socioeconomic status was taken into consideration. Access to computers at school had a positive impact in only 15 of the 29 countries for which this data was available. Our research, for 14-year-olds also found a small, positive impact of computer ownership (which we equate to computer access at home) for the mid-range socioeconomic classes (Figure 2). And we found that whether the teacher used computers as pedagogical tools (which we considered equivalent to access of computers at school) had no impact on the student's grades (Figure 4).

Regarding frequency of computer use, OECD (2006) found that, in general, low frequency users had lower grades than mid-range users and that high frequency users also had a lower grade than mid-range users. We found that to be also true among 14-year-olds, in some socioeconomic classes, but we found that the high frequency users had lower grades that the non-users, and that was very consistent across the different socioeconomic classes (Figure 1). 
Thus, our results are reasonably consistent with these three other reports. Our results agree with those of Johnson (2000) regarding computer use by teachers, and agree with OECD (2006) regarding frequency of computer use, and computer ownership. Our no-impact result for computer use in schools agrees with at least some of the countries studied in OECD (2006). The countries for which OECD (2006) found no significant positive impact of computers at schools were: Australia, Germany, Iceland, Ireland, Italy, Korea, Latvia, New Zealand, Portugal, Thailand, Turkey and Uruguay ${ }^{4}$ It is not clear to us what are the commonalities between these countries and Brazil. Our results disagree more strongly with the ones in Harrison et al. (2003), regarding frequency of computer use.

\subsection{Conclusions}

Faced with our field studies observations that the introduction of computers in schools was not clearly correlated to an increase in academic performance, we decided to go beyond executing case studies. We examined the aggregate data derived from a sample survey and testing data of the nation's school population. We were particularly fortunate in that for the year 2001, students and teachers responded to questions regarding computer use and Internet access.

The result of this national level analysis found a statistically significant reduction of test grades for students that use computer frequently. This was particularly pronounced among the younger and the poorer students. We also

$\overline{4}$ For Greece and Tunisia OECD (2006) found a significant negative impact of computers in schools. 
found a statistically negative impact of Internet access at home for younger students, and a positive impact for 11th graders. Finally, the use of computer and Internet as pedagogical tools in schools had no impact in the students' grades.

While it is necessary to conduct closer research to produce a deeper understanding of the nature of these relationships, it is also necessary to act to prevent what is potentially an educational disaster, one that may not only be confined to Brazil, but potentially to other developing countries. Our research suggests, at least in Brazil and possibly in other countries, public policies which provide computers to poorer students or to their schools must be closely evaluated, because they may in fact be producing an effect that is quite the opposite to the one they intended to produce.

\section{References}

Abdi, H., 2007. The bonferonni and sidak corrections for multiple comparisons. In: Salkind, N. (Ed.), The Encyclopedia of Measurement and Statistics. Sage, Thousand Oaks (CA).

Bland, J. M., Altman, D. G., 1995. Statistics notes: Multiple significance tests: the Bonferroni method. BMJ 310 (6973), 170-.

URL http://www.bmj.com

CCEB, 2003. http://www.abep.org/codigosguias/ABEP_CCEB.pdf.

David, P. A., 1990. The dynamo and the computer: An historical perspective on the modern productivity paradox. American Economic Review 80 (2), $355-361$.

de C. P. Santos, L. L., 2002. Public policies for the Brazilian curricular pa- 
rameters. Educ. Soc. 23 (80), 346-367, in portuguese.

Dwyer, T., 1997. Office workers, engineers and authors: order and change among Brazilian teenage computer users. Teoria \& Sociedade 2, 125-175, in portuguese.

Dwyer, T., 2003. Informatization in secondary education: a sociological approach. In: Ruben, G., Wainer, J., Dwyer, T. (Eds.), Informatica, organizações e sociedade no Brasil. Cortez, pp. 189-222, in portuguese.

Harrison, C., Comber, C., Fisher, T., Haw, K., Lewin, C., Lunzer, E., McFarlane, A., Mavers, D., Scrimshaw, P., Somekh, B., Watling, R., 2003. Impact2: The impact of information and communication technologies on pupil learning and attainment. DfES: London.

Johnson, K. A., 2000. Do computers in the classroom boost academic achievement? a report of the heritage center for data analysis. Tech. Rep. CDA0008, Heritage Foundation, Washington.

Kulik, J., 2003. Effects of using instruciotnal technology in elementary and seconday schools: What controlled evaluation studies say. Tech. rep., SRI International.

OECD, Jan 2006. Are students ready for a technology-rich world?: What PISA studies tell us.

Soares, J. F., Alves, M. T. G., 2003. Racial inequalities in the Brazilian primary education system. Educação e Pesquisa 29 (1), 147-165, in portuguese.

Soares, J. F., Cesar, C. C., Mambrini, J., 2000. Relative influence of family and school factors on student cognitive achievement: a Brazilian experience. Presented at the Annual Meeting of the American Educational Research Association.

Triplett, J. E., 1999. The solow productivity paradox: What do computers do to productivity? Canadian Journal of Economics 32 (2), 309-334. 
Wenglinsky, H., 1997. Does it compute? the relationship between educational tecnology and student achievement in mathematics. Tech. rep., Educational Testing Services, Princeton, NJ. 


\section{Figure Captions}

- Figure 1: Average test results per student frequency of computer use

- Figure 2: Average test results for computer ownership

- Figure 3: Average test results for Internet access at home

- Figure 4: Average test results for teacher use of computer

- Figure 5: Average test results for teacher use of Internet

\section{Tables}

\begin{tabular}{lrrrrrrrrr}
\hline Grade & \multicolumn{7}{c}{ Socioeconomic class } & & Total \\
& & & & & & & & \\
& $\mathrm{a} 2$ & $\mathrm{~b} 1$ & $\mathrm{~b} 2$ & $\mathrm{c}$ & $\mathrm{d}$ & $\mathrm{e}$ & \\
\hline 4th & 578 & 1800 & 4708 & 17904 & 17809 & 3974 & 46773 \\
& & & & & & & \\
8th & 882 & 2610 & 6062 & 20203 & 16892 & 2072 & 48721 \\
11 th & 632 & 1805 & 4143 & 12451 & 10863 & 1221 & 31115 \\
\hline
\end{tabular}

Table 1: Number of students for each grade and for each socioeconomic class 


\begin{tabular}{|c|c|c|c|c|}
\hline & this work & $\begin{array}{l}\text { Harrison et al. } \\
(2003)\end{array}$ & Johnson (2000) & OECD (2006) \\
\hline year & 2001 & $1999-2002$ & 1998 & 2003 \\
\hline \multirow[t]{2}{*}{ country } & Brazil & UK & USA & around $\quad 30$ \\
\hline & & & & OECD countries \\
\hline ages & $10,14,17$ & $11,14,16$ & 10,14 & 15 \\
\hline subject & $\begin{array}{l}\text { Math and Read- } \\
\text { ing }\end{array}$ & $\begin{array}{l}\text { Math, Reading, } \\
\text { and Science }\end{array}$ & Reading & Math \\
\hline variables & $\begin{array}{l}\text { - frequency of } \\
\text { comp. use } \\
\text { - comp. and } \\
\text { Internet at } \\
\text { home } \\
\text { - use of comp. } \\
\text { and Internet } \\
\text { by teachers }\end{array}$ & $\begin{array}{l}\text { - frequency of } \\
\text { comp. use in } \\
\text { class, in } \\
\text { school, and at } \\
\text { home }\end{array}$ & $\begin{array}{l}\text { - comp. use in } \\
\text { class }\end{array}$ & $\begin{array}{l}\text { - access to } \\
\text { comp., } \\
\text { - familiarity } \\
\text { with comp., } \\
\text { - frequency of } \\
\text { use }\end{array}$ \\
\hline \multicolumn{2}{|c|}{ socioeconomicyes } & no & yes & yes \\
\hline
\end{tabular}

Table 2 Comparison with similar studies. 
Figures

Frequency of computer use

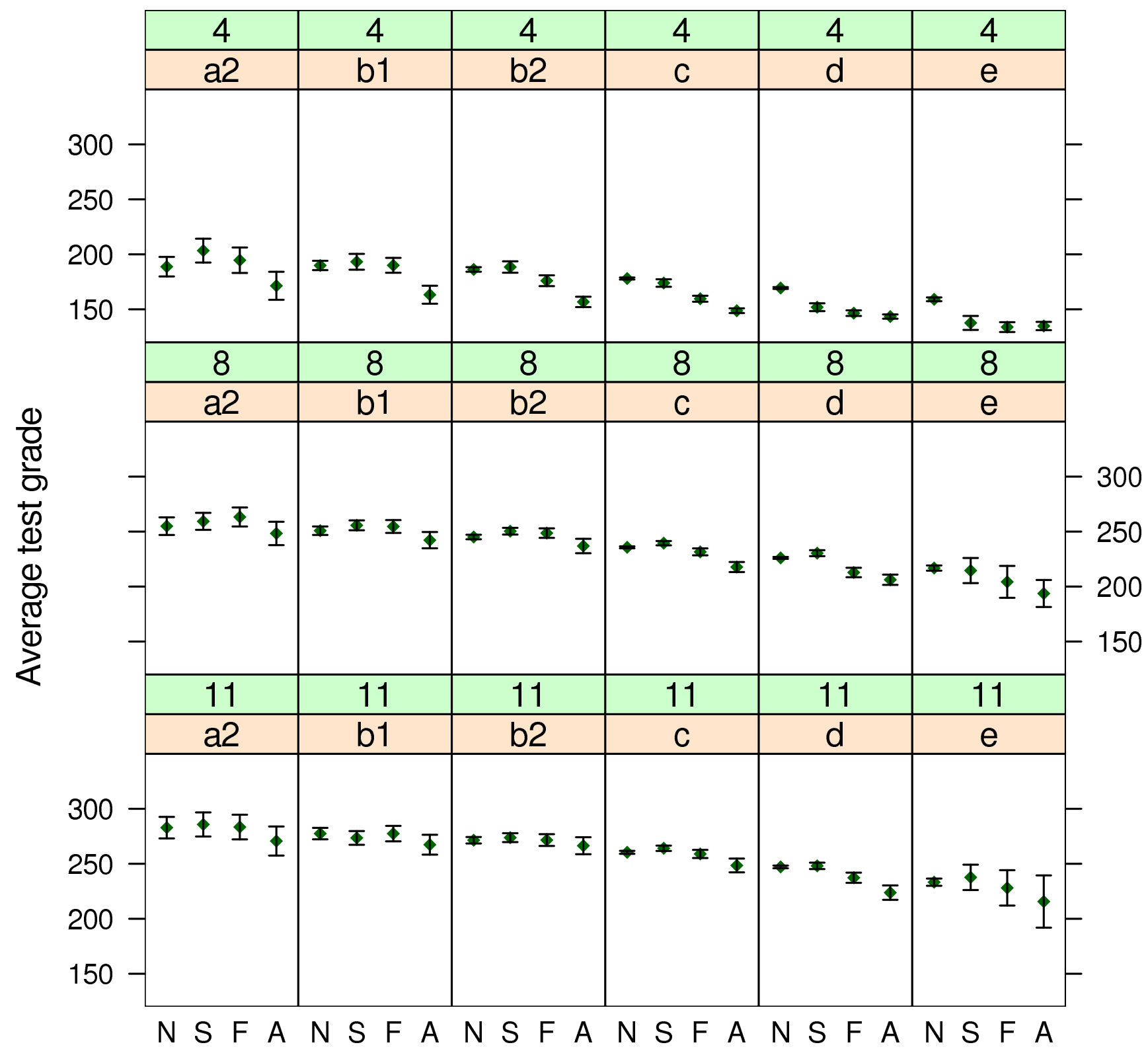

Fig. 1. Average test results per student frequency of computer use 
Computer ownership (by student)

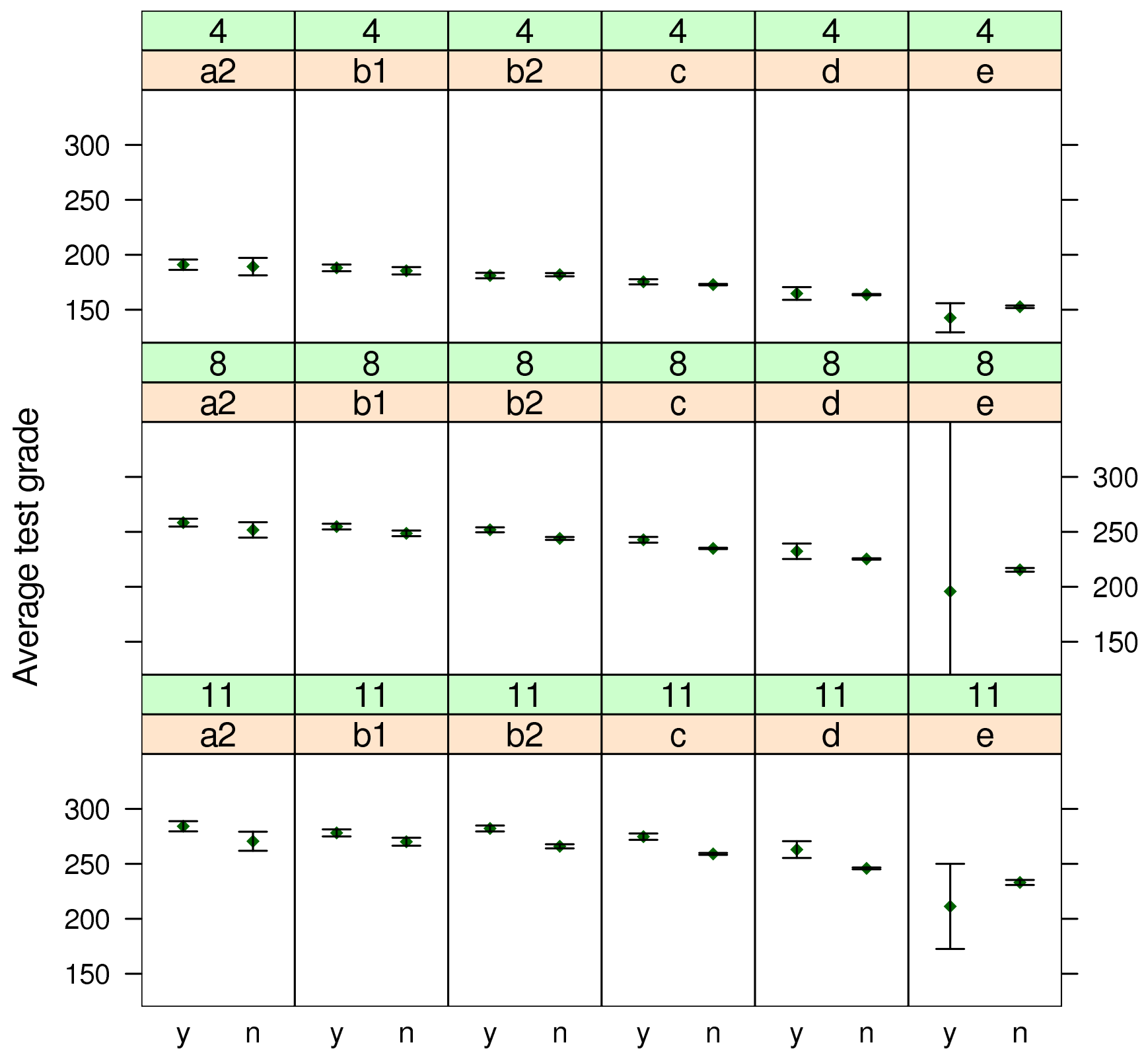

Fig. 2. Average test results for computer ownership 


\section{Internet access (by student)}

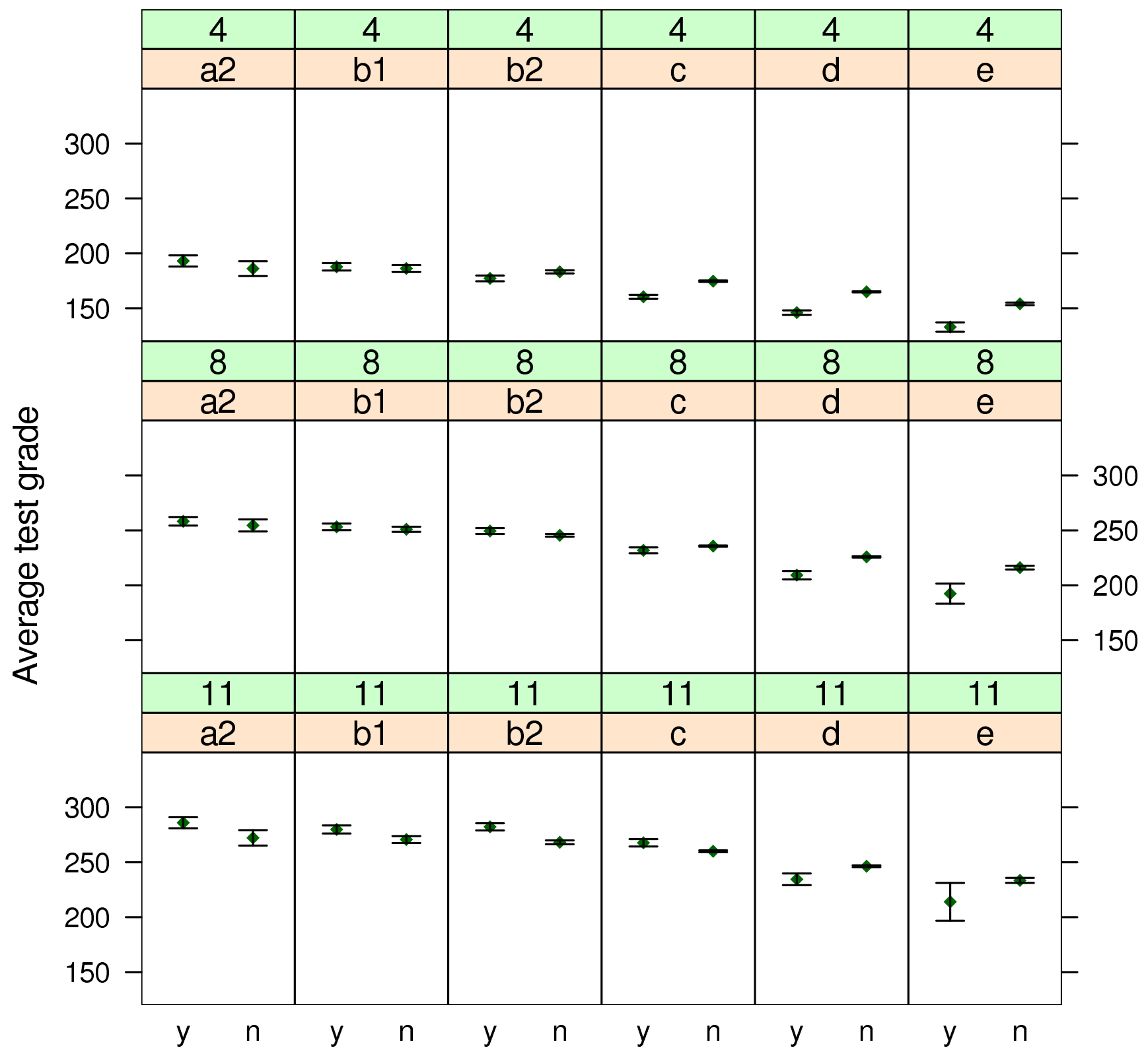

Fig. 3. Average test results for Internet access at home 


\section{Computer use (by teacher)}

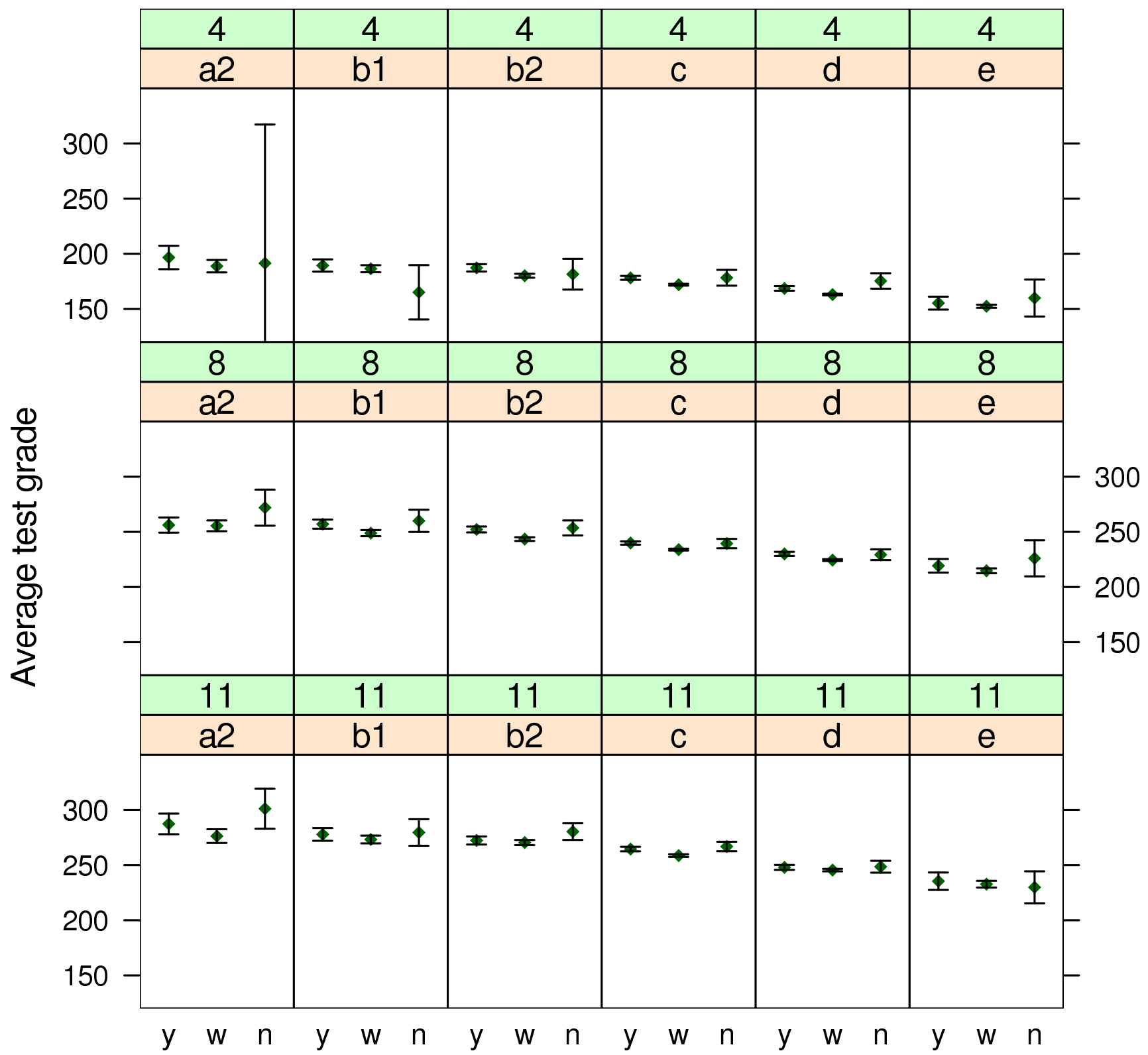

Fig. 4. Average test results for teacher use of computer 
Internet use (by teacher)

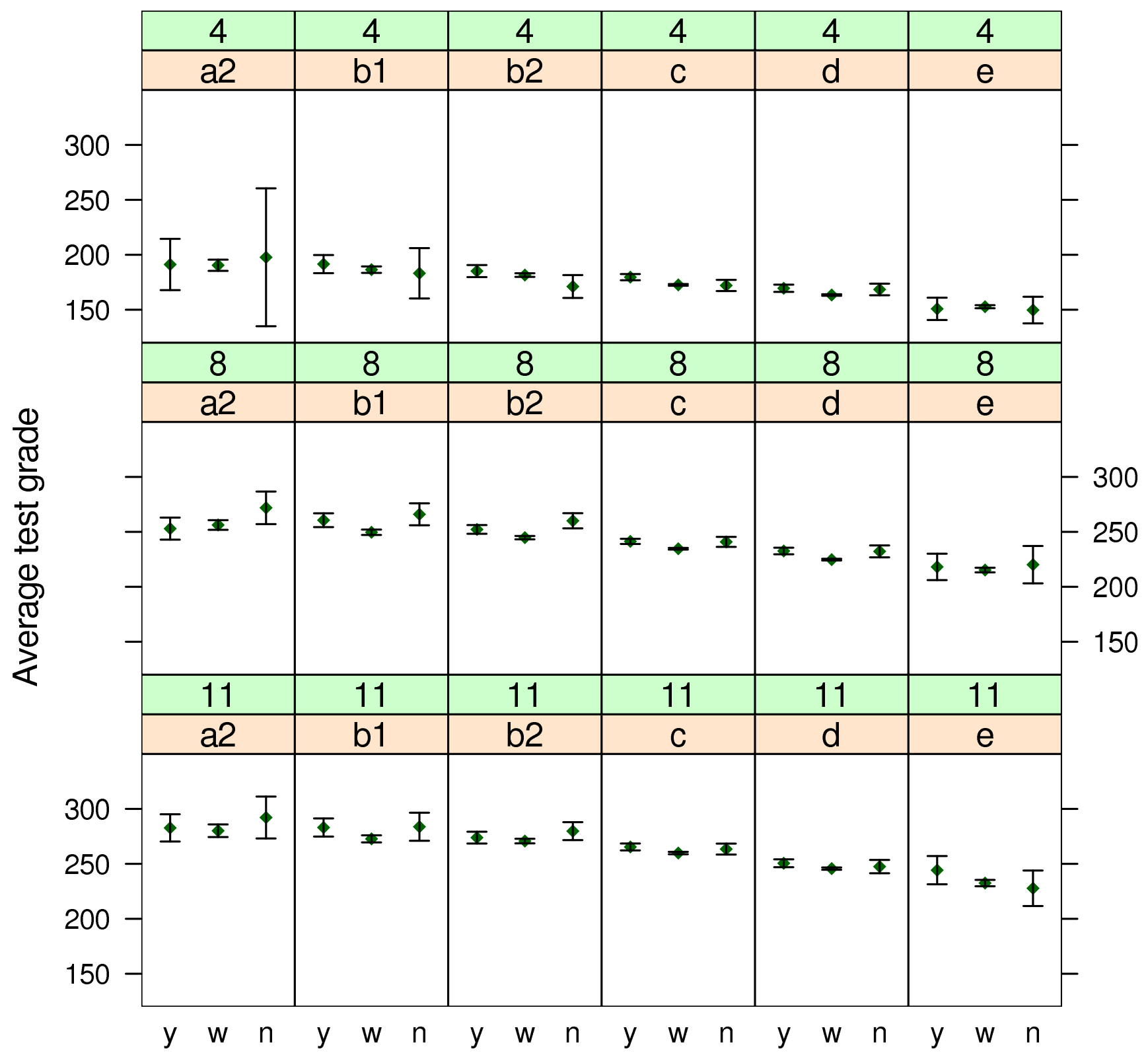

Fig. 5. Average test results for teacher use of Internet 